\title{
Editorial Responsibilities: Both Sides of the Coin
}

\author{
Judit Dobránszki ${ }^{1}$ \\ Jaime A. Teixeira da Silva² \\ ${ }^{1}$ Research Institute of Nyíregyháza, University of Debrecen, Nyíregyháza, P.O. Box 12, H-4400, Hungary \\ Email: dobranszki@freemail.hu \\ 2P. O. Box 7, Miki-cho post office, Ikenobe 3011-2, Kagawa-ken, 761-0799, Japan \\ Email: jaimetex@yahoo.com
}

Doi:10.5901/jesr.2016.v6n3p9

\begin{abstract}
In traditional publishing, authors are usually held accountable by editors. Rarely, however, are editors held accountable by authors, except for extreme cases of misconduct or editorial abuse. This letter seeks to fortify the notion that editors and authors should be held equally accountable for their publishing records and ethical positions, and that editors with tainted publishing records should be removed from their editorial positions. Failure to do so would negatively affect the journal and publisher's image.
\end{abstract}

Keywords: accountability; author-editor-publisher triad; errors in the literature; post-publication peer review; responsibility

\section{Editor's Responsibilities}

Editors have a tremendous responsibility in ensuring the accuracy of the scientific record that they release to the public and in holding the authorship accountable. Editors are thus expected, according to editorial codes of conduct (COCs), to hold themselves to the highest levels of scrutiny, no different to authors (ESF, 2011; Teixeira da Silva, 2013). Editorial responsibilities include (Kleinert and Wager, 2011): responsibility for all that is published (new and old); fair and unbiased decision-making, and policies that are clear to the authorship and public; transparency and honesty; safe-guarding the literature's integrity by pursuing cases of alleged misconduct and correcting the literature using errata, corrigenda, expressions of concern and retractions; clear conflict of interest policies. Spier (2002) argues that authors and editors are unable to function without bias but that scientists can in effect hold editors accountable by adopting "a healthy scepticism and to check wherever possible by collateral evidence (source of publication, ...), papers in the literature, or by directly testing the reliability of each publication." Thus, the intrinsic and inherent presence of bias in publishing should serve as the premise to always be alert and skeptical of what has been published.

\section{Editors' Ethical or Professional Infractions under the Microscope}

Although the responsibilities of editors are fairly well explored in the literature, what is not well explored is what should happen to editors should they fail to meet these responsibilities, or show an imperfect academic or publishing track record. Errors that are detected need to be corrected, and it is incumbent upon authors and editors to work together to achieve this. Failure to do so has been suggested to constitute a form of misconduct (Kamoun and Zipfel, 2016). The issue of editors who make the same publishing or ethical infractions, or who violate their COCs, has not been explored. Editors who violate such COCs or have a less than perfect publishing track record, including retractions, expressions of concern, especially those that are related to duplications, plagiarism or self-plagiarism, when these have been deemed to be unethical by the majority of the peer community, should also be labeled as misconduct, removed from editorial boards and undergo an institutional investigation. In the case of editors, a zero tolerance policy should thus be implemented given their leadership role.

\section{Conclusions}

Editors serve as the gate-keepers of a journal's quality, screen for scientific accuracy, and verify misconduct. Although 
editors' responsibilities are well explored in COCs and the literature, to be expanded upon in a follow-up paper, consequences for editorial infractions are not. Authors and the public have the right to challenge the editorial status quo if their challenge is valid and appropriate, to avoid the phenomenon of inequality that can be interpreted as "all animals are equal but some are more equal than others" (Animal Farm by George Orwell).

\section{Conflict of Interest Statement}

The authors declare no conflicts of interest.

\section{References}

ESF (The European Science Foundation) (2011) The European Code of Conduct for Research Integrity. http://www.esf.org/fileadmin/Public_documents/Publications/Code_Conduct_ResearchIntegrity.pdf (last accessed: 25 July, 2016)

Kamoun, S., Zipfel, C., 2016 Scientific record: Class uncorrected errors as misconduct. Nature, 531, 173. doi: 10.1038/531173e

Kleinert, S., Wager, E., 2011. Responsible research publication: international standards for editors. A position statement developed at the $2^{\text {nd }}$ World Conference on Research Integrity, Singapore, July 22-24, 2010. Chapter 51 in: Mayer T \& Steneck N (eds) Promoting Research Integrity in a Global Environment. Imperial College Press / World Scientific Publishing, Singapore, pp. 317328

Spier, R.E., 2002. On dealing with bias. Science and Engineering Ethics, 8, 4, 483-484. doi: 10.1007/s11948-002-0001-x

Teixeira da Silva, J.A., 2013. Responsibilities and rights of authors, peer reviewers, editors and publishers: a status quo inquiry and assessment. The Asian and Australasian Journal of Plant Science and Biotechnology, 7, Special Issue 1, 6-15. 